\section{ON THE CHLORAL HYDRATE.}

By WILLTAM ALEXANDER, M.D., F.R.C.P., SENIOR PHISICTAN TO THE HALIFAX INFIRMABY AND DISPENSARY.

IN this somewhat remarkable agent, as was observed by Dr. Richardson, we have an instance of the intimate alliance of physiological and chemical investigations as augmenting the resources of the medical practitioner. The few trials already made of its use in this neighbourhood, as a somnolent anodyne especially, have led me to regard it as possessed of considerable therapeutical power, and to prophesy that it is destined to stand side by side with (the option of) the various preparations of opium, devoid, however, of their too commonly observed stupefying, astringent, and nauseating properties. It will not, probably, prove to medicine what chloroform has been to surgery, nor realise the expectations of MM. Liebriech and Dumas; but, irrespective of much error, extravagant speculation, and some risk to human life, there is at the present time a field of inquiry opening out in regard to the agency of certain novel drugs and new methods of administration of old ones which is sure to receive attention and cultivation by the profession. But little is yet known of the influence of medicines hypodermically introduced, or the precise physiological action of alcohol, chloroform, ether, ozone, methylene, and other volatile anæsthetics; and yet this class of agents, together with a marked advance in diagnosties, may be regarded as a characteristic epoch of modern medicine.

Freed from the restraint of the schools, as of old, ingenuity is now taxed in every department to discover some new remedy for the ills to which flesh is heir, and especially to encounter some of the most confessedly fatal diseases. Hence, inter alia, during the last few months only, we have the chloral for delirium tremens, chorea, and the large class comprehended as neuroses, in procuring sleep and resolving muscular contraction; the Calabar bean for tetanus, as in a well drawn-up and successfully-treated case at Chester, as described in THE LANCET of the 18th of December, 1869 ; the exclusive milk diet, and the oxidising agency of the ozonic ether, in the decomposition of the sugar in the blood of diabetic patients; the balsam copaiba in ascites, \&c.; and the transfusion of bloud and ammoniacal liquor into the veins for puerperal fever, and the like. The search, indeed, for specifics has been endless; but, unhappily, with such limited suceess as to lead the sceptics in medicine to reduce their number to three.

With respect to the chloral hydrate and its physiological action, our confrères in Berlin and Paris have spoken in no measured terms of commendation. One very eminent physician says: "Chloroform and Chloral have hitherto been investigated only from an abstract theoretical point of view, but have now taken their place amongst the most precious therapeutical agents." It is a peculiar substance, inasmuch as it derives its solid form by the admixture of the tenuous colourless liquid chloral with water. Chloral $\left(\mathrm{C}_{2} \mathrm{Cl}{ }_{3} \mathrm{OH}\right)$ in appearance resembles chloroform, but on the addition of about an equal measure of water it is transformed into an opaque solid body, very like the carbonate of ammonia, with a pungent odour, smooth feel, and slightly caustic taste. Therapeutically considered, this crystal hydrate is undoubtedly a powerful sedative, motor and sensory; but, in my experience, more a hypnotic than an anæsthetic, for, during the sleep procured, pinching the skin displayed the presence of well-defined reflex action; so that, assuming, as is alleged, a change in the human organism into formic acid and chloroform, its action is not identical with that of the latter fluid, which suspends both sensation and motion. In toxic doses of six grammes and upwards, the anæsthesia might become more complete. Its gradual elimination from the system is supposed to be effected by the alkali of the blood converting it into a chloride of sodium and formiate of soda. In M. Bouchut's practice the hydrate is described as "the sedative in gout, nephritic colic, dental caries, and intense chorea," the quickest and most efficacious in its operation. In common with narcotics generally, the combination of chloral with morphia or chloroform, by the skin or inhaled, is attended with greatly enhanced power, in diminishing sensitive irritability, which is usually the source of reflex action. Into the mysteries of the molecular action of these remedies, and their interrogation of the various organs, it is not the object of this communication to penetrate.

The successes already witnessed lead me to entertain a favourable opinion of the efficacy of the chloral as applicable in a very comprehensive class of distressing nervous affections, in which it has displayed some striking somnolent power. Amongst several other instances, a puerperal case which I saw in consultation with Mr. E. Hamerton, of Elland, in this neighbourhood, is worthy of mention in illustration of my dictum. The patient had exhibited great perturbation of the sensorium in visions and spectral illusions during a week's almost entire wakefulness, for which he had given 30 grains of the bromide of potassium and several cutaneous injections of morphia with little or no beneficial results, when at length a dranght containing 40 grains of the chloral was followed by an immediate and tranquil slumber of twelve hours, succeeded by marked improvement in the cerebral disturbance. In reduced doses the medicine has been since continued with favourable results; and in a note received yesterday, reporting the convalescence, that gentleman relates another example, and expresses his confidence in the power of the new remedy in suitable cases.

The sample of the hydrate used here was four ounces procured through Messrs. Clarke, of York, probably from Hearon and Squire, or Messrs. Zimmermann. The price of 7s. an ounce seems high when its composition is considered, but much care no doubt is needed in its accurate preparation.

Halifax, Necember 30th, 1369.

\section{REMARKS ON THE MANAGEMENT OF THE IMPERIAL HOSPITAL AT VIENNA.}

By G. V. POORE, M.B.,

RESIDENT MEDTCAL OFFICER TO VMIVERSITY COLLEGE HOSPITAL.

THe object of this paper is not to make comparison between the Imperial Hospital at Vienna and St. Bartholomew's Hospital, London, but to lay before the readers of Tre LanCET a brief sketch of the pecuniary and medical management of one of the largest civil hospitals in the world, to compare it with the management of our London hospitals in general, and to show how the Austrian system differs from our own, in what respects it is better, and in what worse. In the table given below some of the items of expenditure at Vienna and St. Bartholomew's are arranged in parallel columns, not for the sake of drawing an exact comparison (an impossibility, to attempt which would be absurd), but rather for the purpose of showing in a rough way what are the main differences in expenditure between Austrian and English hospitals. St. Bartholomew's has been selected because it is one of our largest hospitals, and because its expenditure is not only one of the most common topics of conversation at the present time, and shows probably a maximum of expensiveness, but also because the full statement thereof which so lately appeared in THE LANCET is easy of access to all who may be interested in the matter.

The Vienna Hospital has 2000 beds. The number of outpatients is inconsiderable, and nuany of the beds are filled with cases such as, in England, would be treated at the out-patient department. It is manifestly impossible to compare an hospital of this kind with one of our London hospitals, the beds of which are filled almost entirely by acute cases, and whose out-patients, numbered by tens of thousands, help in no inconsiderable degree to swell the annual accounts.

The Vienna Hospital, being a Government institution, publishes no yearly balance-sheet. For the facts embodied in this paper I am indebted to the kindness of Herr von Mulbäuser, the civil manager, who most politely furnished me with an elaborate manuscript containing the accounts in detail. The rarious sums were given in Austrian cur. 